\title{
POTENTIAL DIFFERENCES ACROSS THE BOUNDARIES BETWEEN SOLUTIONS OF MIXED UNIVALENT CHLO. RIDES
}

\author{
By Edgar Reynolds Smith
}

ABSTRACT

Potential differences across the boundaries between solutions of mixed univalent chlorides were measured using a flowing junction and silver-silver chloride electrodes. There is no evidence of complex formation, and the constant ion conductance principle which MacInnes has shown to be valid in solutions of pure univalent chlorides is probably equally valid in their mixtures.

\section{CONTENTS}

I. Introduction

II. Apparatus.

III. Materials.

IV. Experimental results

V. Discussion

VI. Summary

\section{INTRODUCTION}

In this investigation liquid junction potentials of the types

$$
\begin{array}{r|l}
\mathrm{NaCl}\left(0.1 x_{1}\right) & \mathrm{HCl}\left(0.1-0.1 x_{2}\right) \\
\mathrm{HCl}\left(0.1-0.1 x_{1}\right) & \mathrm{NaCl}\left(0.1 x_{2}\right) \\
\mathrm{HCl}(0.1) & \begin{array}{l}
\mathrm{NaCl}(0.1 x) \\
\mathrm{HCl}(0.1-0.1 x)
\end{array}
\end{array}
$$

were measured. The total concentration on each side of boundary was kept at 0.1 normal. $X$ represents the molal proportion of sodium chloride to the total electrolyte. These junctions appeared to be of interest because of their bearing, in general, on modern theories of electrolytic solutions and, in particular, on the validity of the transference and ion-conductance relations found by MacInnes. The measurements were made with a "flowing" junction between the solutions, using a modification of the apparatus of Lamb and Larson. ${ }^{1}$

It has been shown by MacInnes ${ }^{2}$ that the chloride ion conductance is the same, at a given concentration, in solutions of the alkali chlorides and hydrochloric acid; that is, $N_{C l} \lambda$ =constant where $N_{C l}$ is

1 Lamb and Larson, J. Am. Chem. Soc., 42, p. 229; 1920.

MacInnes, J. Am. Chem. Soc., 43, p. 1217; 1921; MacInnes and Cowperthwaite, Trans. Faraday Soc., 23, p. 400; 1927. 
the chloride ion transference number and $\lambda$ is the equivalent conductance of any such solution. In other words, the conductance of the ion constituents is an additive property for such solutions at a given concentration. This was found to hold accurately within the concentration range of 0.01 to 1.0 normal. MacInnes ${ }^{3}$ and Braley and Rippie ${ }^{4}$ have shown that transference data on mixtures of these chlorides are in accord with the same simple additivity of conductances of the ion constituents. The transference numbers of the ions in the mixtures can, therefore, be expressed in terms of the transference numbers in solutions of the pure salts at the same concentration as the total concentration of the mixture. In the case of a mixture of sodium chloride and hydrochloric acid the expression for the hydrogen ion transference number is

$$
T_{H}=\frac{N_{H}\left(1-N_{N a}\right)}{\left(N_{H}-N_{N a}\right)+\left(1-N_{H}\right) / x}
$$

where $N_{H}$ and $N_{N a}$ are the transference numbers of the hydrogen and sodium ions in the solutions of the pure salts each at the total concentration of the mixture, and $x$ is the ratio of the number of mols of sodium chloride in the mixture to the total concentration. If the same relations are applied in the derivation of the formula for the potential difference across the boundaries between solutions of these mixed chlorides, as represented in (1), the result ${ }^{5}$ is

$$
E=\frac{R T}{F} \ln \frac{\left(1-N_{N a}\right)-x_{2}\left(N_{H}-N_{N a}\right)}{\left(1-N_{N a}\right)-x_{1}\left(N_{H}-N_{N a}\right)}
$$

and for a junction of type (2), where $x_{1}=0$,

$$
E=\frac{R T}{F} \ln \frac{\left(1-N_{N a}\right)-x\left(N_{H}-N_{N a}\right)}{\left(1-N_{N a}\right)}
$$

Formula (3) can be obtained from (4) by taking the difference between two expressions for $E$ according to (4). For this reason only one measurement was made on a junction of type (1) to test the validity of the general relation, and a series of determinations was made on junctions of type (2).

A similar series of measurements, incidental to another investigation, has been carried out by Ferguson and Bacor. ${ }^{6}$ using a "static" junction and calomel electrodes with cells of the type

$$
\mathrm{Hg} ; \mathrm{HgCl} \text {, satd. } \mathrm{KCl}|\mathrm{HCl}(0.1)| \begin{aligned}
& \mathrm{NaCl}(0.1 x) \\
& \mathrm{HCl}(0.1-0.1 x)
\end{aligned} \mid \text { satd. } \mathrm{KCl}, \mathrm{HgCl} ; \mathrm{Hg}
$$

3 MacInnes, J. Am. Chem. Soc., 47, p. 1922; 1925.

4 Braley and Rippie, J. Am. Chem. Soc., 49, p. 1493; 1927.

5 MarInnes, J. Am. Chem. Soc., 48, p. 2831; 1926.

6 Ferguson and Bacon, J. Am. Chem. Soc., 49, p. 1921; 1927. 


\section{APPARATUS}

The cell used is shown diagrammatically in Figure 1. It includes a junction of the type described by MacInnes and Yeh. ${ }^{7}$ A junction of this type in all probability gives a "mixture" boundary; that is, in the thin layer between the two solutions the composition changes progressively from that of the one solution to that of the other, the total concentration of electrolyte, however, remaining the same at all points in the junction. A mixture boundary is assumed in deriving equations (3) and (4).

A thermostat of about 85 liters capacity, containing well-stirred liquid petrolatum and provided with a inercury contact regulator and a heater, held the temperature constant at $25^{\circ} \pm 0.05^{\circ}$ as measured

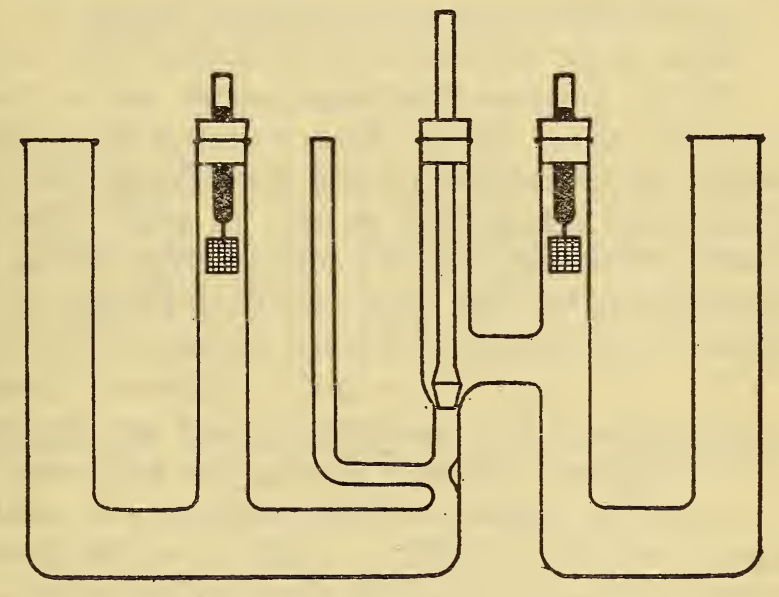

Figure 1

with a calibrated thermometer graduated in $0.2^{\circ}$ divisions and read with an attached magnifying glass.

The electromotive force determinations were made with a Leeds \& Northrup type $\mathrm{K}$ potentiometer and a recently certified standard cell.

\section{MATERIALS}

Hydrochloric acid of constant boiling point was prepared, and its composition was checked by determining the chloride as $\mathrm{AgCl}$. The two chloride analyses agreed to 1 part in 4,000 .

The sodium chloride was purified by precipitation with hydrochloric acid gas from a filtered solution of the c. p. salt. The salt thus obtained was dried and heated in a platinum dish until it began to fuse. 
The solutions were made up by weighing out portions of the stock solution of the acid and of the salt and adding the proper weight of water to make the solutions contain 0.1 equivalent of chloride to $1,000 \mathrm{~g}$ of water. All weights were reduced to vacuum.

\section{SILVER-SILVER CHLORIDE ELECTRODES}

Contrary to the report of Randall and Young, ${ }^{8}$ electrolyticaily plated silver-silver chloride electrodes on a base of platinum were found to be satisfactory and reproducible as judged by intercomparison. They were prepared as follows: To start with, eight pieces of platinum gauze $1.3 \mathrm{~cm}$ square, welded to platinum wires sealed into glass tubes, ${ }^{9}$ were coated with silver from a solution of potassium silver cyanide and soaked for 10 days in changes of distilled water. The silver thus deposited was never removed during the course of the work. These silver electrodes were divided into two sets of four each. The day previous to a measurement each set was coated electrolytically with silver chloride from a central larger silver-silver chloride electrode of the same type in a crystallizing dish filled with solution of the same composition as that in which the electrodes were to be used. Following this, the central electrode was removed, the solution discarded, the dish filled with fresh solution of the same composition, and the electrodes allowed to stand in this solution overnight. The next day the potential differences between the different combinations of two electrodes in each set were measured. Of the 117 combinations compared during the work only one pair differed by as much as $0.1 \mathrm{mv}$, and the variation was usually of the order of magnitude of 0.02 to $0.03 \mathrm{mv}$. After a run the silver chloride on the electrodes was converted into silver by electrolysis, chloride being plated on the central larger electrodes. The silver electrodes thus re-formed were then ready for conversion into silver-silver chloride electrodes in the proper solutions, as before.

\section{EXPERIMENTAL RESULTS}

With the flowing junction apparatus used, a rate of flow of 5 to 10 drops a minute was found to give a liquid junction potential which did not vary more than about $0.1 \mathrm{mv}$ during the time taken (from one to two hours) for a determination. Readings were made every five minutes and the results reported here are their averages.

The values of $N_{\mathrm{Na}}$ and $N_{\mathrm{H}}$ applied in Equations (3) and (4) were 0.3864 and 0.8320 , respectively. ${ }^{10}$ Substitution of these values in (4) gives the equation

$$
E=0.05915 \log _{10}(1-0.7262 x) \text { at } 25^{\circ}
$$

\footnotetext{
${ }^{8}$ Randall and Young, J. Am. Chem. Soc., 50, p. 989; 1928.

- MacInnes and Beattie, J. Am. Chem. Soc., 42, p. 1132; 1920.

10 Smith and MacInnes, J. Am. Chem. Soc., 4\%, p. 1009; 1925.
} 
Table 1 shows the measured values, including the value, marked with an asterisk, of MacInnes and Yeh for the junction.

TABLE 1.-Potential differences across the junctions of $0.1 \mathrm{~N}$ hydrochloric acid and $0.1 \mathrm{~N}$ mixtures of hydrochloric acid and sodium chloride

\begin{tabular}{|c|c|c|c|c|}
\hline No. & $x$ & $\begin{array}{c}\text { Measured } \\
\text { emf }\end{array}$ & $\begin{array}{c}\text { Calculated } \\
\text { emf }\end{array}$ & Difference \\
\hline $\begin{array}{l}1 .-. \\
2-- \\
3-- \\
4 \ldots \\
5 \ldots\end{array}$ & $\begin{array}{l}0.2346 \\
.5050 \\
.6142 \\
.7518 \\
.8931\end{array}$ & $\begin{array}{l}m v \\
4.75 \\
11.85 \\
15.12 \\
20.17 \\
26.80\end{array}$ & $\begin{array}{l}m v \\
4.80 \\
11.73 \\
15.17 \\
20.28 \\
26.87\end{array}$ & $\begin{array}{c}\text { Per cent } \\
-1.1 \\
+1.0 \\
-.33 \\
-.55 \\
-.26\end{array}$ \\
\hline & $\begin{array}{r}.8997 \\
.9400 \\
1.000 \\
1.000\end{array}$ & $\begin{array}{r}27.18 \\
29.41 \\
33.17 \\
+33.09\end{array}$ & $\begin{array}{l}27.14 \\
29.48 \\
33.28 \\
33.28\end{array}$ & $\begin{array}{l}+.15 \\
-.23 \\
-.33 \\
-.57\end{array}$ \\
\hline
\end{tabular}

Measurement by MacInnes and Yeh.

\section{$\mathrm{HCl}(0.1) \mid \mathrm{NaCl}(0.1)$}

The latter result is the average of three determinations yielding $33.07,33.13$, and $33.07 \mathrm{mv}$ and is in good agreement with the corresponding value found in this work, which is the average of two determinations yielding 33.166 and $33.171 \mathrm{mv}$. The percentage differences between measured and calculated values are given in the last column.

TABLE 2.-Measurements by Ferguson and Bacon of the liquid junction potentials

\begin{tabular}{|c|c|c|c|}
\hline$x$ & $\begin{array}{c}\text { Measured } \\
\text { emf }\end{array}$ & $\underset{\text { emf }}{\text { Calculated }}$ & Difference \\
\hline $\begin{array}{l}0.04 \\
.1 \\
.4 \\
.8 \\
1.0\end{array}$ & $\begin{array}{r}m v \\
1.05 \\
2.04 \\
8.23 \\
20.97 \\
30.15\end{array}$ & $\begin{array}{l}m v \\
0.76 \\
1.94 \\
8.82 \\
22.35 \\
33.28\end{array}$ & $\begin{array}{c}\text { Per cent } \\
+28 \\
+4.9 \\
-7.2 \\
-5.1 \\
-10\end{array}$ \\
\hline
\end{tabular}

The cell

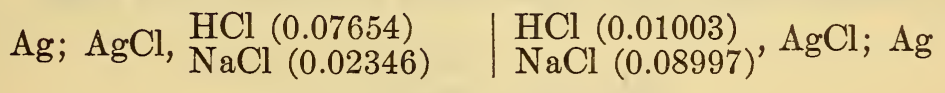

in which $x_{1}=0.2346$ and $x_{2}=0.8997$ was measured to test the general relation given by equation (3). The value found was $22.39 \mathrm{mv}$ as an average of two runs which yielded the values 22.425 and $22.359 \mathrm{mv}$. If value No. 1 is subtracted from No. 6 in Table 1, it is seen that 22.43 $\mathrm{mv}$ is the liquid junction potential of this cell measured by difference in good agreement with the calculated value of $22.34 \mathrm{mv}$ as well as with the direct determination.

The electromotive force values for similar "static" junctions reported by Ferguson and Bacon are shown in Table 2. Their cells 
contained three liquid junctions, and in view of the $3 \mathrm{mv}$ difference between their value for the simple junction

\section{$\mathrm{HCl}(0.1) \mid \mathrm{NaCl}(0.1)$}

and the value given by MacInnes and Yeh, which was confirmed in the present work, it is probable that definite reproducible measurements can not be made by their method.

\section{DISCUSSION}

Evidence has been given by Harned ${ }^{11}$ that the activity of the chloride ion is the same, within the precision limits of liquid-junction measurements, at any one total electrolyte concentration in different mixtures of hydrochloric acid with the alkali chlorides. The silversilver chloride electrode potentials are, therefore, balanced in the cell within the accuracy of these measurements, and the measured electromotive force is thus the potential difference across the liquid junction.

The hypotheses involved in the calculation of these liquid-junction potentials by equations (3) and (4) are:

(a) The same degree of dissociation of each chloride in each mixture.

(b) Substantially constant chloride ion activities in univalent chloride mixtures of the same (dilute) total concentration. This, as Bronsted ${ }^{12}$ has pointed out, can be strictly true only in very dilute solutions.

(c) The constancy of the product $T_{\mathrm{C} 1} \lambda$ in each such mixture. Included in $(a)$ is the absence of complex formation. Substantially complete dissociation is consistent with $(a)$. The agreement of the calculated with the measured potential differences is evidence for the validity of these hypotheses, at least for dilute mixtures of univalent chlorides, within the precision limits of these determinations.

\section{SUMMARY}

The potential differences across liquid junctions of the types

$$
\mathrm{HCl}(0.1) \mid \begin{aligned}
& \mathrm{HCl}(0.1-0.1 x) \\
& \mathrm{NaCl}(0.1 x)
\end{aligned}
$$

\begin{tabular}{l|l}
$\mathrm{HCl}\left(0.1-0.1 x_{1}\right)$ & $\mathrm{HCl}\left(0.1-0.1 x_{2}\right)$ \\
$\mathrm{NaCl}\left(0.1 x_{1}\right)$ & $\mathrm{NaCl}\left(0.1 x_{2}\right)$
\end{tabular}

were measured using a flowing junction and silver-silver chloride electrodes. In contrast to the static-junction measurements on such boundaries, as made by Ferguson and Bacon, these flowing junction 
determinations give reproducible values for the liquid-junction potentials which can be accurately computed from the formula

$$
E=\frac{R T}{F} \ln \frac{\left(1-N_{\mathrm{Na}}\right)-x_{2}\left(N_{\mathrm{H}}-N_{\mathrm{Na}}\right)}{\left(1-N_{\mathrm{Na}}\right)-x_{1}\left(N_{\mathrm{H}}-N_{\mathrm{Na}}\right)}
$$

where $x_{1}$ and $x_{2}$ represent the molal proportions of sodium chloride to the total electrolyte concentration, and $N_{\mathrm{Na}}$ and $N_{\mathrm{H}}$ are the cation transference numbers in solutions of the pure electroly tes at the same concentration as the total concentration of the mixture.

Washington, December 8, 1928.

$47559^{\circ}-29-10$ 